\title{
Dynamic and static performance optimization of dual active bridge DC-DC converters
}

\author{
Nie HOU ${ }^{1}$, Wensheng SONG ${ }^{1}$, , Yutong $\mathrm{ZHU}^{2}$, Xiao SUN ${ }^{1}$, Wei $\mathbf{L I}^{2}$ \\ MPCE
}

\begin{abstract}
High efficiency and fast dynamic response are two main control objectives for dual active bridge (DAB) DC-DC converters. Traditional extended phase shift (EPS) control can significantly enhance the conversion efficiency of DAB DC-DC converters by reducing current stress; however, it cannot fulfill fast dynamic response requirements. In this paper, a novel hybrid control scheme consisting of EPS control and direct power control (DPC), named as EPS-DPC, is proposed. EPS-DPC control has salient features in both efficiency and dynamic performance. In order to verify the outstanding performance of the proposed EPS-DPC scheme, an experimental comparison was carried out on a scale-down DAB DC-DC converter among several control strategies, including single phase shift control with traditional voltage-loop (SPS-
\end{abstract}

CrossCheck date: 16 May 2017

Received: 5 February 2017/Accepted: 26 July 2017/Published online: 19 December 2017

(C) The Author(s) 2017. This article is an open access publication

$\triangle$ Wensheng SONG

songwengsheng@163.com

Nie HOU

nie_hou@126.com

Yutong ZHU

zhuyt117@sina.com

Xiao SUN

1151204571@qq.com

Wei LI

carslw@yahoo.cn

1 School of Electrical Engineering, Southwest Jiaotong University, Chengdu 610031, China

2 Locomotive \& Car Research Institute, China Academy of Railway Sciences, Beijing 100081, China
TVL), EPS control with traditional voltage-loop (EPSVTL), and EPS-DPC. Experimental results have been high consistent with theoretical analysis, and verified these advantages of the proposed EPS-DPC scheme.

Keywords Current stress, Efficiency, Dynamic response, Dual active bridge (DAB) DC-DC converter, Extended phase shift control, Direct power control

\section{Introduction}

Dual active bridge (DAB) DC-DC converters have several advantages, such as bidirectional power flow, high power density, easy implementation of zero-voltage switching, convenient access to cascading and parallelism. As a result, these converters are widely used in the distributed generation systems [1-3], DC-micro-grid systems [4], electric vehicle charging systems [5-8], energy storage systems $[9,10]$, and power electronic transformers in railway locomotive applications $[11,12]$.

In applications mentioned above, it is significant to achieve robust dynamic performances of DAB DC-DC converters under challenging circumstances, such as input voltage fluctuation, output load disturbance, and etc. Various advanced control schemes have been proposed to enhance the dynamic response. Firstly, dynamic characteristics of DAB DC-DC converters were analyzed by the small-signal modeling and the discrete-time average modeling methods [13-15]. A feed-forward compensation strategy [16], which feedbacks the load current to the control system, was used to improve transient response of DAB DC-DC converters in the load disturbance conditions. However, a table lookup is essential for the feed-forward strategy, which makes it less applicable in complex 
operation conditions. Besides, a model-based phase-shift (MPS) control was also developed to improve dynamic response under load disturbance $[17,18]$. Meanwhile, high efficiency is another critical requirement for DAB DC-DC converters. Switching strategies utilizing off-line computation have capability in minimizing power losses [19, 20]. However, consecutive optimal control cannot be realized by these strategies. Reducing current stress and power reflow in a DAB DC-DC converter can increase efficiency as well [21]. Extended phase shift (EPS) control, which is able to largely improve efficiency by reducing current stress, was introduced in [4]. However, when EPS control was adopted to DAB DC-DC converters, there usually exists slow dynamic response issues.

Direct power control (DPC) scheme is a popular active solution to enhance dynamic performance of AC-DC or DC-AC converters [22, 23]. It is well known for its strong abilities to improve dynamic and static performances of power converters. However, there are few reports about the DPC scheme applied in DAB DC-DC converters so far.

By combing EPS control with DPC control, a hybrid scheme EPS-DPC is proposed in this paper. The EPS-DPC scheme unites high efficiency of EPS and great dynamic performance of DPC. As a result, the DAB DC-DC converter using EPS-DPC has advantages in both high efficiency and outstanding dynamic performance.

The paper is organized as follows. SPS and EPS control schemes are introduced and compared in detail in Section 2. In Section 3, EPS-DPC control is proposed, and its derivation from combination of EPS and DPC is included as well. Theoretical comparison of dynamic response performance in EPS and SPS was demonstrated in Section 4. A scale-down DAB DC-DC converter prototype was designed and built to test performance of the proposed EPS-DPC scheme, the EPS control with traditional voltage-loop (EPS-TVL), and the single phase shift (SPS) control with traditional voltage-loop (SPS-TVL). And a comparison of experimental results was carried out in Section 5. Conclusions are drawn from theoretical analysis and experimental results comparison, and then summarized in Section 6.

\section{Theoretical analysis of single phase shift and extend phase shift controls}

A typical topology of a DAB DC-DC converter is shown in Fig. 1, and its equivalent model under phase shift control is shown in Fig. 2.

In Fig. 2, $L$ is the total inductance of the transformer leakage inductor and auxiliary inductor; $U_{\mathrm{ab}}$ and $U_{\mathrm{cd}}$ are the output pulse voltages of $H_{1}$-bridge and $H_{2}$-bridge respectively; $U_{L}$ is the voltage across the inductor, while $i_{L}$

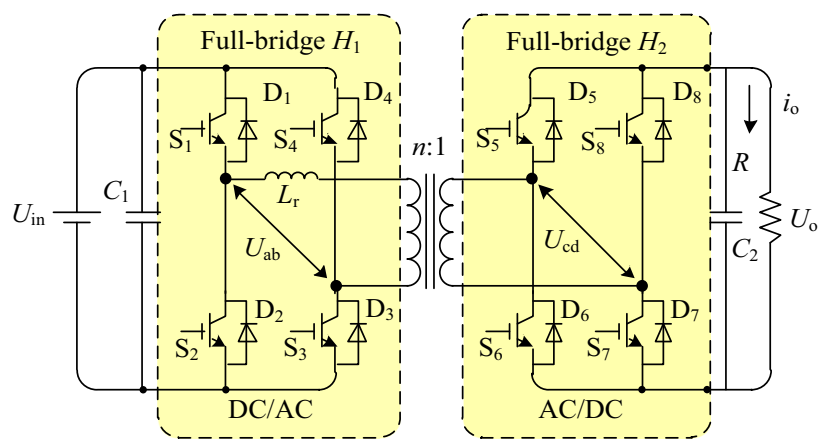

Fig. 1 DAB DC-DC converter topology

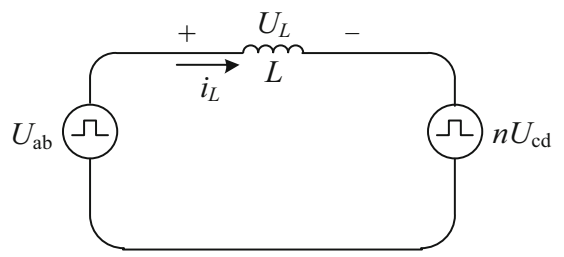

Fig. 2 Equivalent model of DAB DC-DC converter with phase shift control

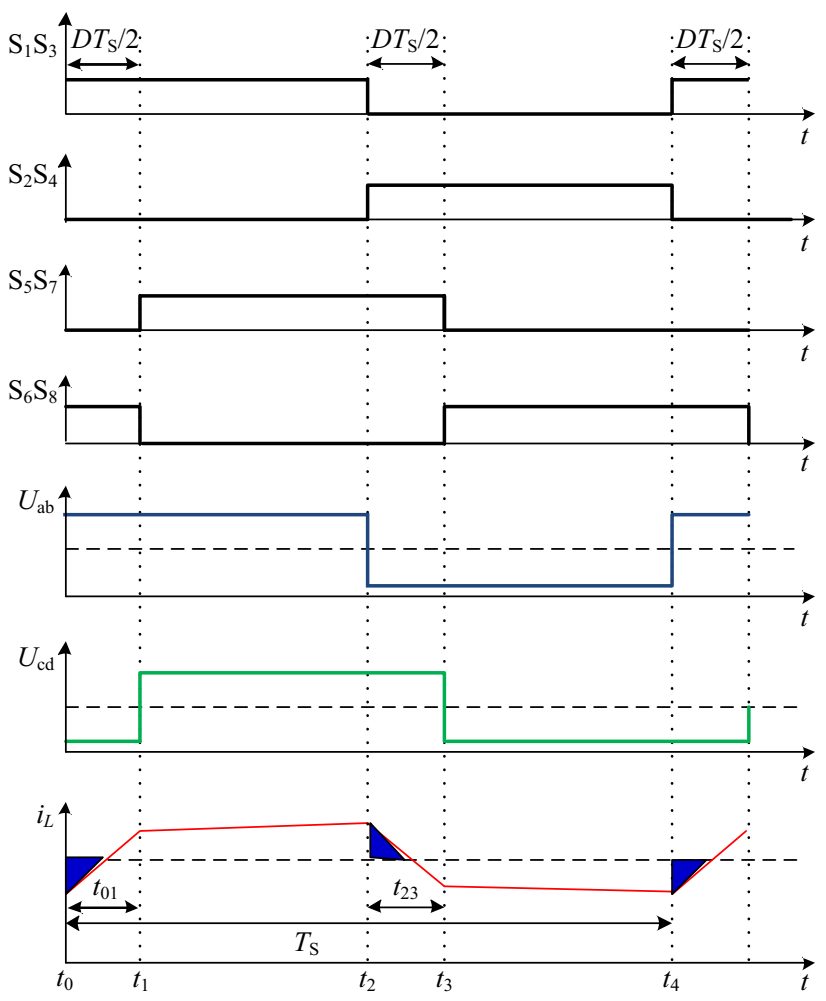

Fig. 3 Waveforms of DAB DC-DC converters with SPS control

is the current through the inductor; $n$ is the transformer voltage conversion ratio.

The main waveforms of a DAB DC-DC converter with SPS control are shown in Fig. 3, where $T_{\mathrm{S}}$ is the switching period, $D$ is the phase shift ratio between $S_{1} S_{3}$ and $S_{5} S_{7}$. 
It can been seen in Fig. 3 that $i_{L}$ is out of phase with $U_{\mathrm{ab}}$ during $t_{0}$ to $t_{01}$ and $t_{2}$ to $t_{23}$ intervals in a switching period. Thus, the transmission power is negative during these intervals, and it is defined as power reflow. Transmission power $P$, power reflow $Q_{\mathrm{S}}$ and current stress $i_{\mathrm{PS}}$ of DAB DC-DC converters with SPS control can be expressed as:

$$
\left\{\begin{array}{l}
P=\frac{n T_{\mathrm{S}} U_{\text {in }} U_{\mathrm{o}}}{2 L} D(1-D) \\
Q_{\mathrm{S}}=\frac{n T_{\mathrm{S}} U_{\mathrm{in}} U_{\mathrm{o}}}{16 L(k+1)}[k+(2 D-1)]^{2} \\
i_{\mathrm{PS}}=\frac{n T_{\mathrm{S}} U_{\mathrm{o}}}{2 L}(2 D-1+k)
\end{array}\right.
$$

where $k$ is the voltage ratio and $k=U_{\text {in }} /\left(n U_{\mathrm{o}}\right) . P, Q_{\mathrm{S}}$ and $i_{P S}$ given in (1) can be further simplified into (2).

$$
\left\{\begin{array}{l}
p=\frac{P}{P_{\mathrm{N}}}=4 D(1-D) \\
q_{\mathrm{S}}=\frac{Q_{\mathrm{S}}}{P_{\mathrm{N}}}=\frac{[k+(2 D-1)]^{2}}{2(k+1)} \\
i_{\mathrm{ps}}=\frac{i_{\mathrm{PS}}}{i_{\mathrm{PN}}}=2(2 D-1+k)
\end{array}\right.
$$

where $P_{\mathrm{N}}$ and $i_{\mathrm{PN}}$ are:

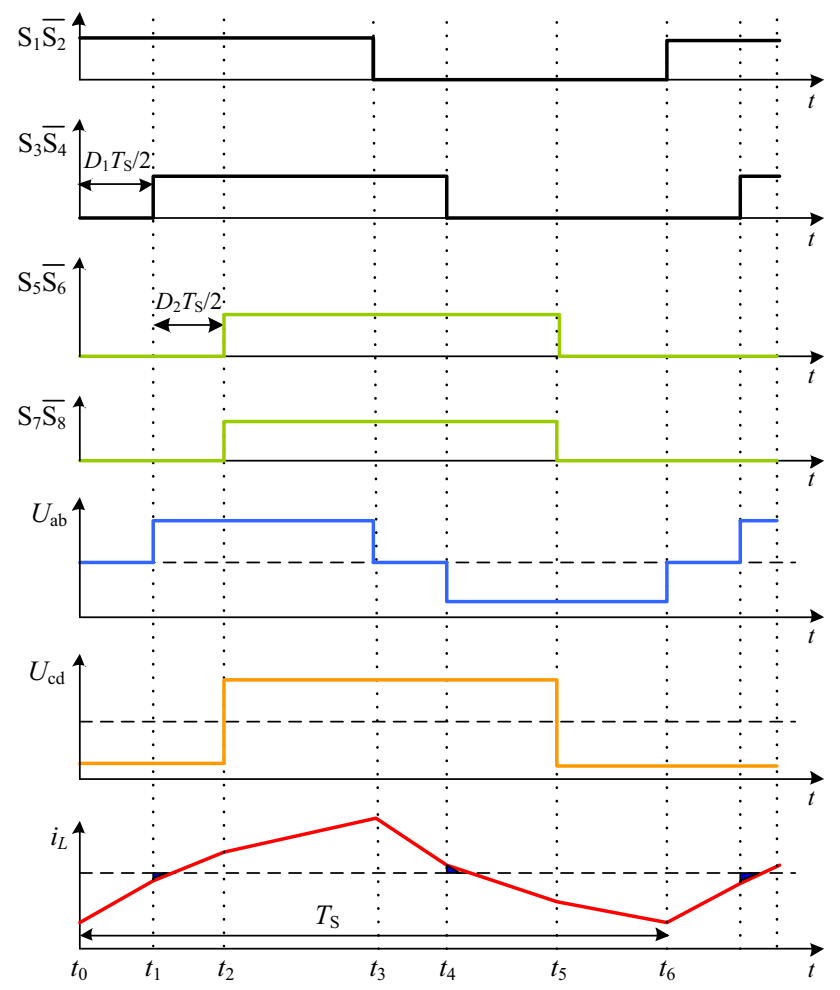

Fig. 4 Waveforms of DAB DC-DC converters with EPS control
$\left\{\begin{array}{l}P_{\mathrm{N}}=\frac{n T_{\mathrm{S}} U_{\mathrm{in}} U_{\mathrm{o}}}{8 L} \\ i_{\mathrm{PN}}=\frac{n T_{\mathrm{S}} U_{\mathrm{o}}}{4 L}\end{array}\right.$

The main waveforms of DAB DC-DC converters with EPS control [4] are shown in Fig. 4. $D_{1}$ is the phase shift ratio between $\mathrm{S}_{1}$ and $\mathrm{S}_{3} ; D_{2}$ is the phase shift ratio between $\mathrm{S}_{3}$ and $\mathrm{S}_{5}, \mathrm{~S}_{7}$.

Similarly, transmission power $P$, power reflow $Q_{\mathrm{E}}$ and current stress $i_{\mathrm{PE}}$ of the DAB DC-DC converter with EPS control can be expressed as:

$$
\left\{\begin{array}{l}
P=\frac{n T_{\mathrm{S}} U_{\text {in }} U_{\mathrm{o}}}{4 L}\left(D_{1}+2 D_{2}-D_{1}^{2}-2 D_{2}^{2}-2 D_{1} D_{2}\right) \\
Q_{\mathrm{E}}=\frac{n T_{\mathrm{S}} U_{\mathrm{in}} U_{\mathrm{o}}\left[k\left(1-D_{1}\right)+\left(2 D_{2}-1\right)\right]^{2}}{16 L(k+1)} \\
i_{\mathrm{PE}}=\frac{n T_{\mathrm{S}} U_{\mathrm{o}}}{2 L}\left[k\left(1-D_{1}\right)+2 D_{1}+2 D_{2}-1\right]
\end{array}\right.
$$

Then, $P, Q_{\mathrm{E}}$ and $i_{\mathrm{PE}}$ can be simplified as:

$$
\left\{\begin{array}{l}
p=2\left(D_{1}+2 D_{2}-D_{1}^{2}-2 D_{2}^{2}-2 D_{1} D_{2}\right) \\
q_{\mathrm{E}}=\frac{\left[k\left(1-D_{1}\right)+\left(2 D_{2}-1\right)\right]^{2}}{2(k+1)} \\
i_{\mathrm{pe}}=2\left[k\left(1-D_{1}\right)+2 D_{1}+2 D_{2}-1\right]
\end{array}\right.
$$

In order to reduce current stress and power reflow of SPS control, a constrained optimization method is adopted [4] under EPS control, and phase-shift ratios $D_{1}$ and $D_{2}$ can be calculated with respect to $D$ under the same transmission power circumstance. Phase-shift ratio $D_{1}$ can be calculated as follow.

$D_{1}=\left\{\begin{array}{lc}\frac{1-\sqrt{2(1-2 D)^{2}-1}}{2} & K<2,0 \leq D<(2-\sqrt{2}) / 4 \\ \frac{1+\sqrt{2(1-2 D)^{2}-1}}{2} & K \geq 2,0 \leq D<(2-\sqrt{2}) / 4 \\ \sqrt{2}(1-2 D) / 2 & (2-\sqrt{2}) / 4 \leq D<1 / 2\end{array}\right.$

Similarly, phase-shift ratio $D_{2}$ can be calculated as follow.

$$
D_{2}= \begin{cases}0 & 0 \leq D<(2-\sqrt{2}) / 4 \\ \frac{1-\sqrt{2}(1-2 D)}{2} & (2-\sqrt{2}) / 4 \leq D<1 / 2\end{cases}
$$

According to (6) and (7), the relationship between $D_{1}$ and $D_{2}$ can be derived as:

$D_{2}=\left\{\begin{array}{lc}0 & 0 \leq D<(2-\sqrt{2}) / 4 \\ \frac{1}{2}-D_{1} & (2-\sqrt{2}) / 4 \leq D<1 / 2\end{array}\right.$

In addition, according to (2), the simplified current stress $i_{\mathrm{ps}}$ and the simplified power reflow $q_{\mathrm{S}}$ in SPS control are 
functions of the simplified transmission power $p$, which are given in (9).

$$
\left\{\begin{array}{l}
i_{\mathrm{ps}}=2(k-\sqrt{1-p}) \\
q_{\mathrm{S}}=\frac{k-\sqrt{1-p}}{2(k+1)}
\end{array}\right.
$$

Similarly, according to (5) and (12), the simplified current stress $i_{\mathrm{pe}}$ and the simplified power reflow $q_{\mathrm{E}}$ in EPS control can be written in functions of the simplified transmission power $p$ as follows.

$$
\begin{aligned}
& i_{\mathrm{pe}}= \begin{cases}k+(2-k) \sqrt{1-2 p} & 0 \leq p \leq \frac{1}{2} \\
2 k-k \sqrt{2-2 p} & \frac{1}{2}<p \leq 1\end{cases} \\
& q_{\mathrm{E}}= \begin{cases}\frac{[k(1+\sqrt{1-2 p})-2]^{2}}{2(k+1)} & 0 \leq p \leq \frac{1}{2} \\
\frac{\left[k\left(1-\sqrt{\frac{1-p}{2}}\right)-2 \sqrt{\frac{1-p}{2}}\right]^{2}}{2(k+1)} & \frac{1}{2}<p \leq 1\end{cases}
\end{aligned}
$$

According to (9)-(11), in SPS and EPS schemes, characteristics of the simplified current stress and simplified power reflow with respect to the unified transmission power $p$ are shown in Fig. 5.

It can be seen from Fig. 5a that both the simplified power reflows in SPS and EPS schemes increase with voltage conversion ratio $k$. Under the same $k$ value, the power reflow with SPS control continuously increases with the increasing of $p$, while the power reflow with EPS control decreases firstly and then increases with $p$ increasing. In the full range of $k$ from 0 to $1, q_{\mathrm{E}}$ of EPS is always smaller than $q_{\mathrm{S}}$ of SPS, which validates that EPS can effectively reduce power reflow, compared with SPS. In addition, it can be concluded from Fig. 5b that both current stresses in SPS and EPS schemes increase with transmission power $p$ at various voltage conversion ratios $k$. Comparison results indicate that EPS reaches smaller current stress than SPS. In conclusion, compared with SPS control, EPS control has advantages in reducing the power reflow and current stress of DAB DC-DC converters at the same time.

\section{Hybrid scheme of EPS control and DPC scheme}

DPC scheme is one of the classical control strategies to improve dynamic performances of power converters $[22,23]$. Since the desired output voltage is always related to the transmission power in voltage-source converters, the transmission power is an important parameter for power converters. The series inductance $L$, the switching period

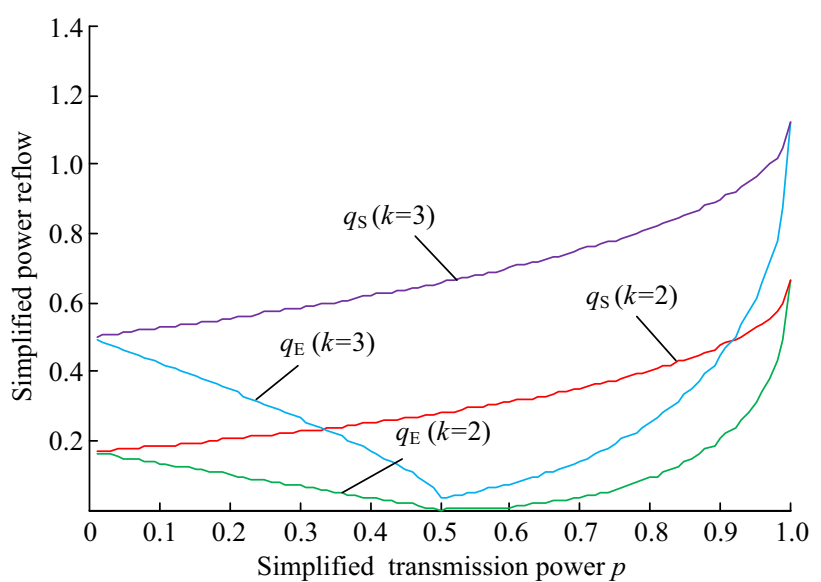

(a) Simplified power reflow and unified transmission power

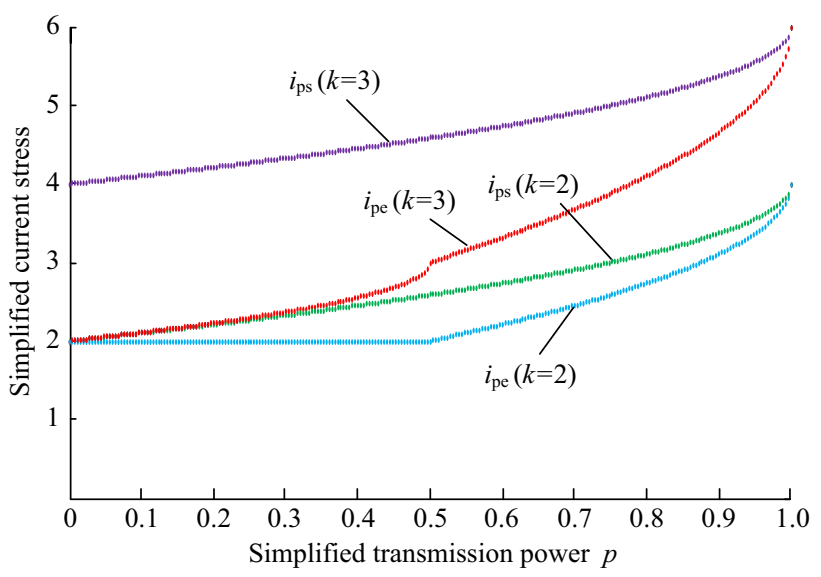

(b) Simplified current stress and unified transmission power

Fig. 5 Characteristics comparison between SPS and EPS controls

$T_{\mathrm{S}}$ and the transformer voltage ratio $n$ can be considered as constant values in the DAB DC-DC converters. Thus, according to (4), the desired transmission power $p^{*}$ in EPSDPC scheme can be defined as:

$p^{*}=\frac{4 L}{n T_{\mathrm{S}}} p=U_{\text {in }} U_{\mathrm{o}}\left(D_{1}+2 D_{2}-D_{1}^{2}-2 D_{2}^{2}-2 D_{1} D_{2}\right)$

Combining (8) and (12), the phase-shift ratios $D_{1}$ can be expressed with $p^{*}$ as:

$D_{1}= \begin{cases}\frac{1}{2}+\sqrt{\frac{1}{4}-\frac{2 p^{*}}{U_{\mathrm{o}} U_{\text {in }}}} & 0 \leq p^{*}<\frac{U_{\mathrm{o}} U_{\text {in }}}{8}, k \geq 2 \\ \frac{1}{2}-\sqrt{\frac{1}{4}-\frac{2 p^{*}}{U_{\mathrm{o}} U_{\text {in }}}} & 0 \leq p^{*}<\frac{U_{\mathrm{o}} U_{\mathrm{in}}}{8}, k<2 \\ \sqrt{\frac{1}{2}-\frac{2 p^{*}}{U_{\mathrm{o}} U_{\mathrm{in}}}} & \frac{U_{\mathrm{o}} U_{\text {in }}}{8} \leq p^{*} \leq \frac{U_{\mathrm{o}} U_{\text {in }}}{4}\end{cases}$

Similarly, the phase-shift $\operatorname{ratios} D_{2}$ can be expressed with $p^{*}$ as: 
$D_{2}= \begin{cases}0 & 0 \leq p^{*}<\frac{U_{\mathrm{o}} U_{\text {in }}}{8} \\ \frac{1}{2}-\sqrt{\frac{1}{2}-\frac{2 p^{*}}{U_{\mathrm{o}} U_{\text {in }}}} & \frac{U_{\mathrm{o}} U_{\text {in }}}{8} \leq p^{*} \leq \frac{U_{\mathrm{o}} U_{\text {in }}}{4}\end{cases}$

According to (14), characteristics of phase-shift ratios and the desired transmission power with uniformization can be seen in Fig. 6.

From Fig. 6, it is clear that when $p^{*}$ is smaller than $0.125 U_{\text {in }} U_{\mathrm{o}}$, the phase-shift ratio $D_{2}$ is equal to zero; and then, with the increase of $p^{*}$, the phase-shit ratio $D_{2}$ gradually increases, and it reaches 0.5 when $p^{*}$ $=0.25 U_{\mathrm{in}} U_{\mathrm{o}}$. Differently, when $p^{*}$ is smaller than $0.125 U_{\mathrm{in}} U_{\mathrm{o}}$, there are two variation trends of the phaseshift ratio $D_{1}$. When $k$ is smaller than 2, $D_{1}$ increases along with $p^{*}$. In contrary, when $k$ is equal to or larger than $2, D_{1}$ decreases as $p^{*}$ increases. Moreover, when $p^{*}$ is larger than $0.125 U_{\text {in }} U_{\mathrm{o}}, D_{1}$ gradually decreases and down to zero when $p^{*}$ increases to $0.25 U_{\text {in }} U_{\mathrm{o}}$.

The optimized phase-shift ratios in the EPS-DPC scheme can be obtained from (14) as well. Figure 7 shows the overall procedure flowchart which is used to estimate the optimized values $D_{1}$ and $D_{2}$, where $p^{*}$ is the output of the voltage outer loop PI controller and represents the unified transmission power reference.

Moreover, according to (8), $D_{2}$ can be expressed with respect to $D_{1}$ in the EPS control system. In order to implement the close-loop control of the EPS control, combining (6)-(8), and $D_{1}$ and $D_{2}$ can be expressed by the output of the PI controller as follows.

$D_{1}= \begin{cases}1 / 2-P I_{\text {out }} & 0 \leq p^{*} 1 / 4, k \geq 2 \\ P I_{\text {out }} & 0 \leq P I_{\text {out }} \quad 1 / 4, k 2 \\ 1 / 2-P I_{\text {out }} & 1 / 4 \leq p^{*} \leq 1 / 2\end{cases}$

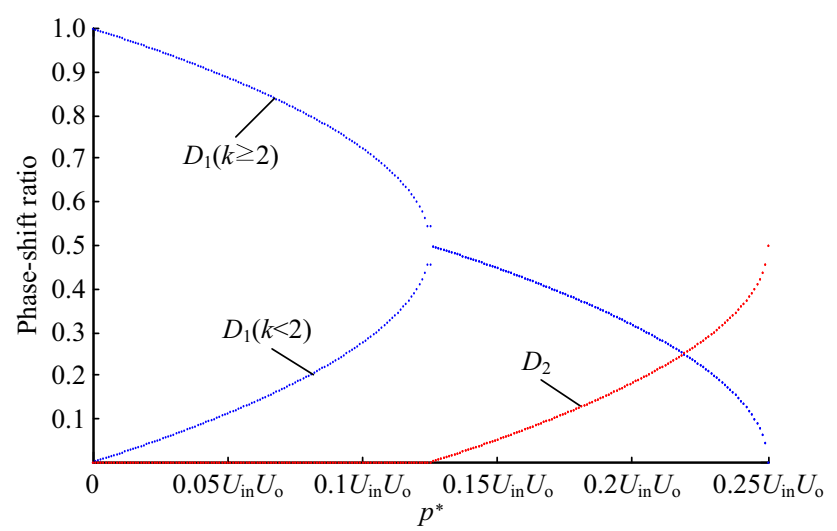

Fig. 6 Characteristics of phase-shift ratios and desired transmission power

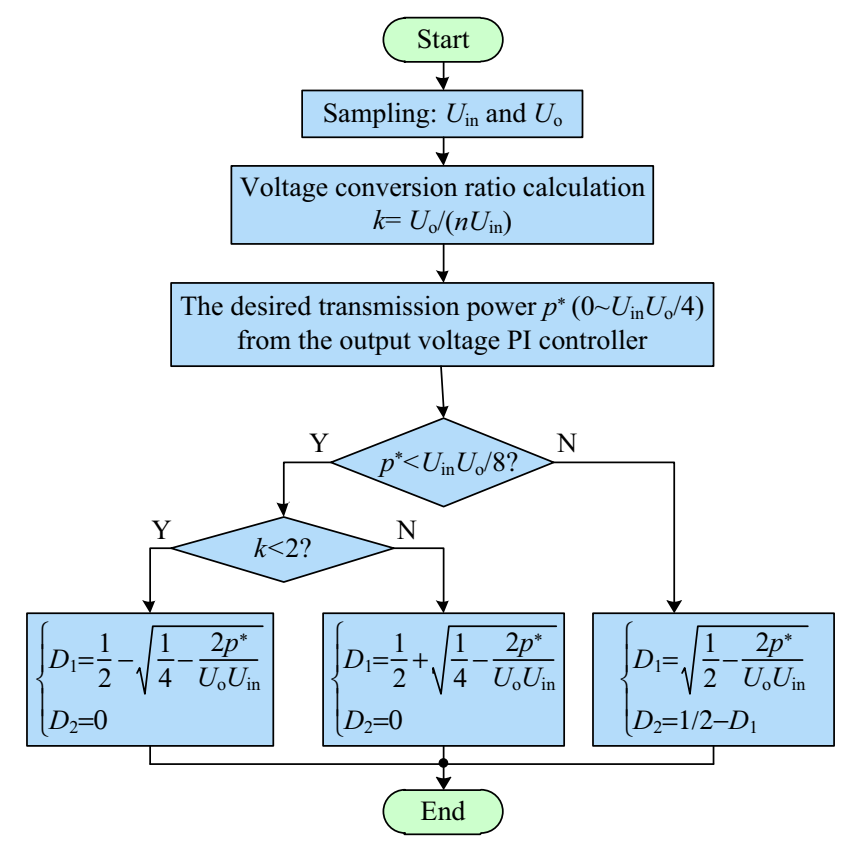

Fig. 7 Calculating procedure of optimal phase-shift ratios in EPSDPC scheme

$D_{2}= \begin{cases}0 & 0 \leq P I_{\text {out }} 1 / 2 \\ P I_{\text {out }} & 1 / 4 \leq p^{*} \leq 1 / 2\end{cases}$

\section{Dynamic response performance comparison of EPS and SPS}

It is essential to analyze the main influence factors on the transmission power. During the dynamic response process, the inductor current may contain DC bias current, which should be considered when calculating the transient transmission power. For a DAB DC-DC converter with SPS control, if the inductor current includes a DC bias component, it has waveforms shown in Fig. 8.

According to Fig. 8, with different initial values of the inductor current $i_{L}\left(t_{0}\right)$, the transmission power can be expressed as:

$$
\begin{aligned}
P & =\frac{1}{T_{\mathrm{S}}} \int_{t_{0}}^{t_{4}} U_{\mathrm{ab}}(t)\left(i_{L}^{\prime}(t)-I\right) \mathrm{d} t \\
& =\frac{1}{T_{\mathrm{S}}} \int_{t_{0}}^{t_{4}} U_{\mathrm{ab}}(t) i_{L}^{\prime}(t)-U_{\mathrm{ab}}(t) I \mathrm{~d} t
\end{aligned}
$$

where $i_{L}^{\prime}(t)$ is the AC component of inductor current $i_{L} ; I$ is the DC component of $i_{L}$. Since the $H_{1}$-bridge output voltage waveform $U_{\mathrm{ab}}(t)$ is a symmetrical square-wave in positive and negative half periods, with amplitude $U_{\text {in }}$, the integral value of component $U_{\mathrm{ab}}(t) I$ in the right side of (17) is zero, and the transmission power $P$ is indicated by $U_{\mathrm{in}}$, $U_{\mathrm{o}}$ and $D$ in form of (18). 


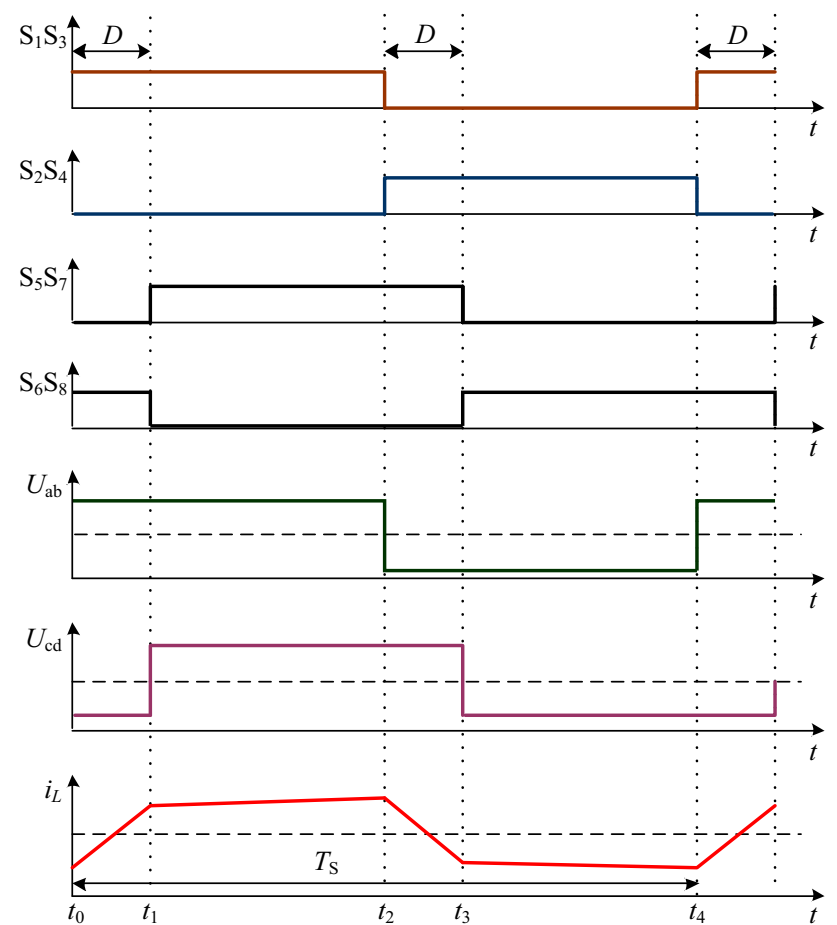

Fig. 8 Waveforms of DAB DC-DC converters with DC bias current under SPS control

$P=\frac{U_{\mathrm{in}} U_{\mathrm{o}} D(1-D) T_{\mathrm{S}}}{2 n L}$

Comparing (1) and (18), it is obvious that $P$ is determined by $U_{\mathrm{in}}, U_{\mathrm{o}}, D, T_{\mathrm{S}}, n$ and $L$ under SPS control no matter what condition the converter operates in. Similarly, the transmission power with EPS control is also only related to the circuit parameters and the phase-shift ratios regardless its operating circumstances.

So, in order to reach the desired output voltage of the DAB DC-DC converter, the desired transmission power obtained from the PI controller can be directly used to calculate the command phase-shift ratios $D_{1}$ and $D_{2}$, which are able to improve the dynamic responses of this converter, compared with the traditional PI controller.

In particular, according to (12)-(14), when the input voltage is changed, the corresponding phase-shift ratios $D_{1}$ and $D_{2}$ can be quickly obtained, because the desired transmission power $p^{*}$ is unchanged with the same load resistance. The waveforms of dynamic procedure under EPS-DPC scheme are shown in Fig. 9.

According to Fig. 9, when the input voltage $U_{\text {in }}$ steps up and down, the desired transmission power $p^{*}$ will keep the same since the output voltage $U_{\mathrm{o}}$ will not change visibly with capacitance $C_{2}$. Then, the phase-shift ratios $D_{1}$ and $D_{2}$ can be calculated by (14) to maintain the same transmission

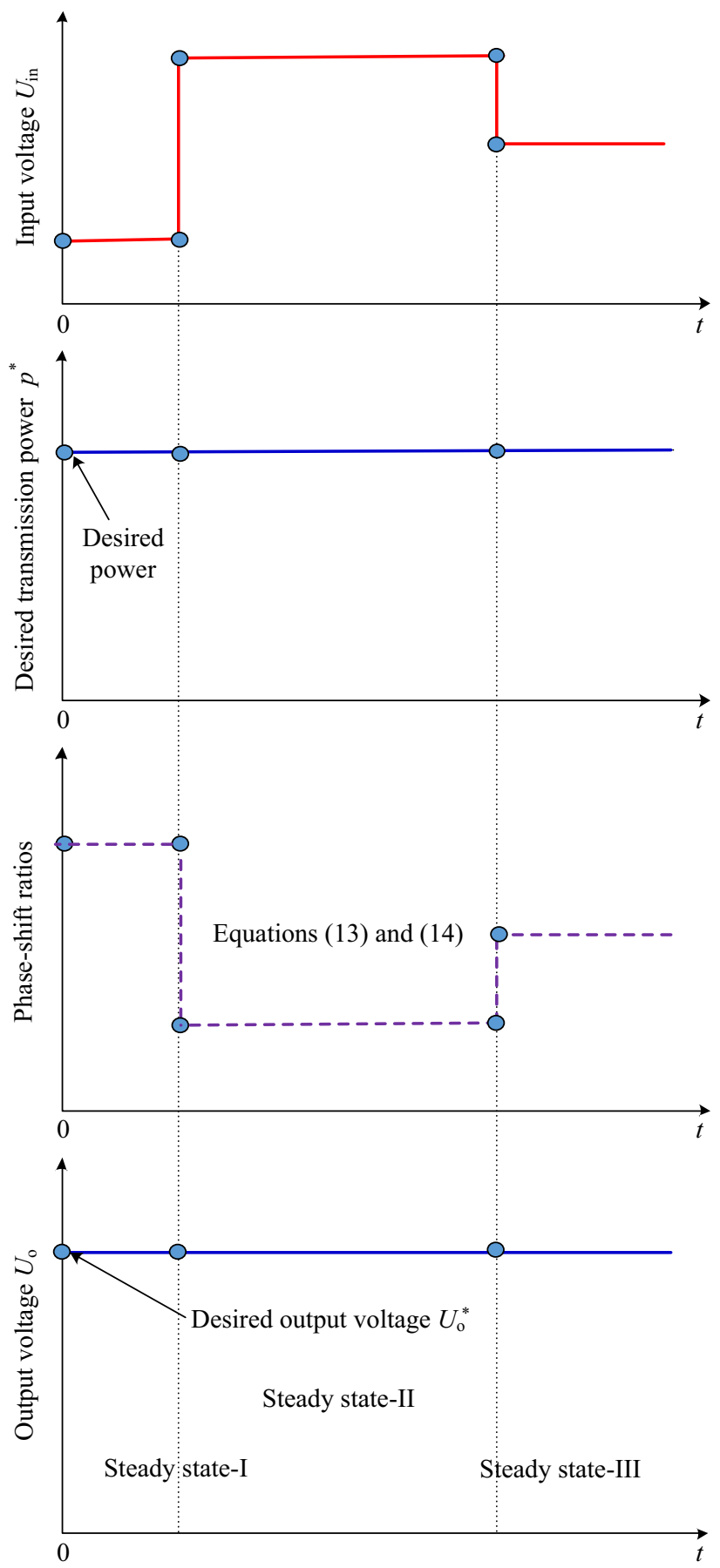

Fig. 9 Waveforms of dynamic procedure under EPS-DPC scheme

power $p^{*}$, and the output voltage $U_{\mathrm{o}}$ will keep in the desired output voltage $U_{\mathrm{o}}^{*}$. Therefore, the EPS-DPC scheme can achieve better dynamic performances of the DAB DC-DC converter.

Moreover, according to (12)-(14), the output voltage $U_{\mathrm{o}}$ is used to describe the phase-shift ratios $D_{1}$ and $D_{2}$, which can act as a negative feedback to calculate the phase-shift ratios $D_{1}$ and $D_{2}$. Hence, the EPS-DPC scheme can also 
improve the dynamic performances when the load resistance is changed.

\section{Experimental results comparison and analysis of EPS-DPC, SPS-TVL and EPS-TVL}

Based on a scale-down DAB DC-DC converter prototype, SPS-TVL, EPS-TVL and EPS-DPC are compared in details. Corresponding block diagrams of these control strategies are given in Figs. 10, 11 and 12. It can be noticed that, in EPS-TVL and EPS-DPC, there is one extra voltage sensor to measure the input voltage when compared with the SPS-TVL scheme.

In order to verify the aforementioned theoretical analysis, an experimental hardware prototype of a DAB DCDC converter is designed with a TMS320F28335 DSP controller of Texas Instruments [24]. The main parameters of the adopted DAB DC-DC converter are listed in Table 1. An experimental comparison of the proposed EPS-DPC scheme, EPS-TVL and SPS-TVL control schemes is carried out on the prototype.

Figure 13 show the experimental waveforms of current stress and efficiency with respect to the input voltage $U_{\text {in }}$ for these three schemes, respectively. It can be noticed in Fig. 13a that EPS-DPC scheme and EPS-TVL scheme present similar results and achieve lower current stress comparing with SPS-TVL scheme. In addition, from Fig. 13b, it is clear that compared with the SPS-TVL control, the EPS-DPC scheme and EPS-TVL control can achieve higher efficiency, especially in high input voltage condition. Thus, it can be summarized that the EPS-DPC and EPS-TVL control schemes can achieve better current stress suppression and higher efficiency in high input voltage condition, compared with SPS-TVL.

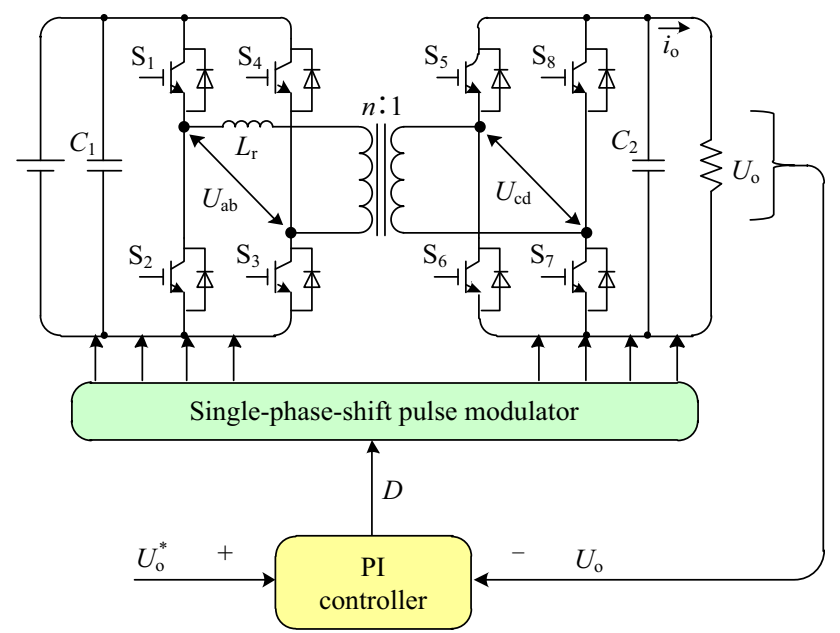

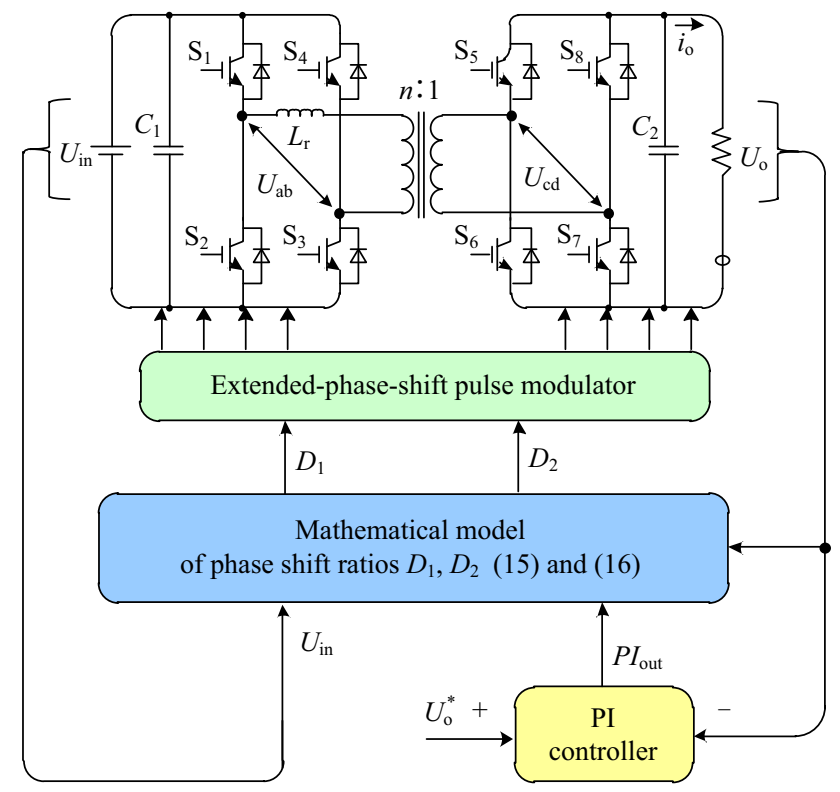

Fig. 11 Block diagram of EPS-TVL scheme

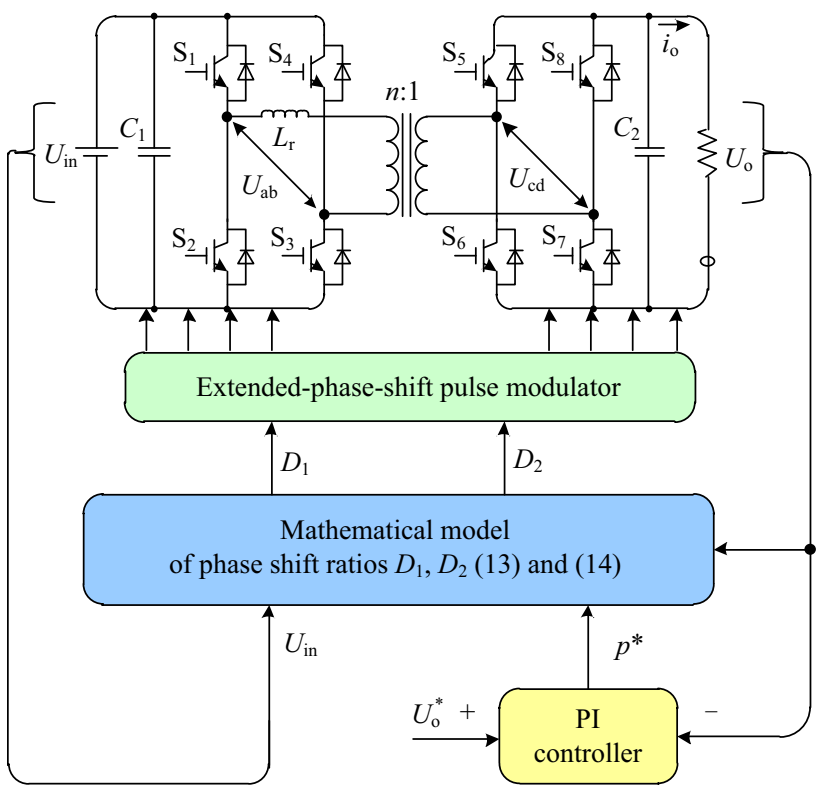

Fig. 12 Block diagram of EPS-DPC scheme

Table 1 Electrical parameters of experimental prototype

\begin{tabular}{ll}
\hline Parameters & Values \\
\hline Transformer turn ratio $(n)$ & 1 \\
Auxiliary inductor $\left(L_{r}\right)$ & $0.2 \mathrm{mH}$ \\
Switching frequency $\left(f_{s}\right)$ & $10 \mathrm{kHz}$ \\
Input-side capacitor $\left(C_{1}\right)$ & $2.2 \mathrm{mF}$ \\
Output-side capacitor $\left(C_{2}\right)$ & $2.2 \mathrm{mF}$ \\
Resistive load $(R)$ & $15,20 \Omega$ \\
\hline
\end{tabular}

Fig. 10 Block diagram of SPS-TVL scheme 


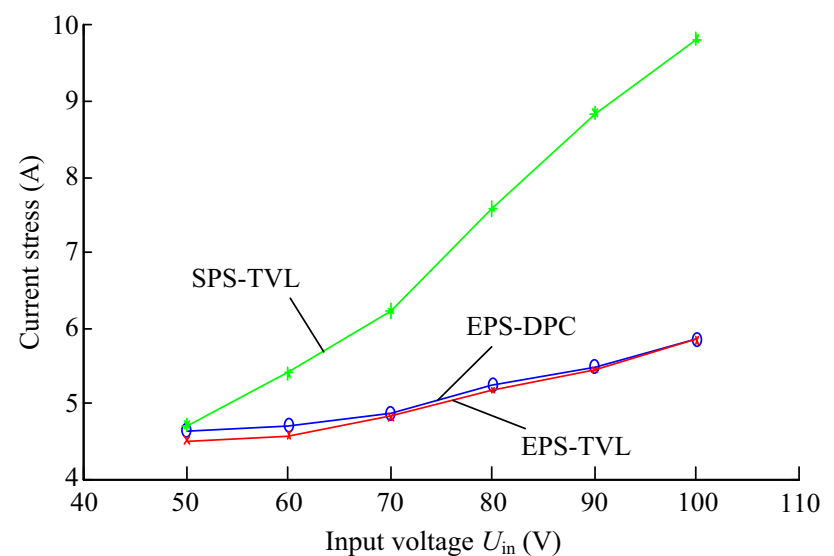

(a) Current stress

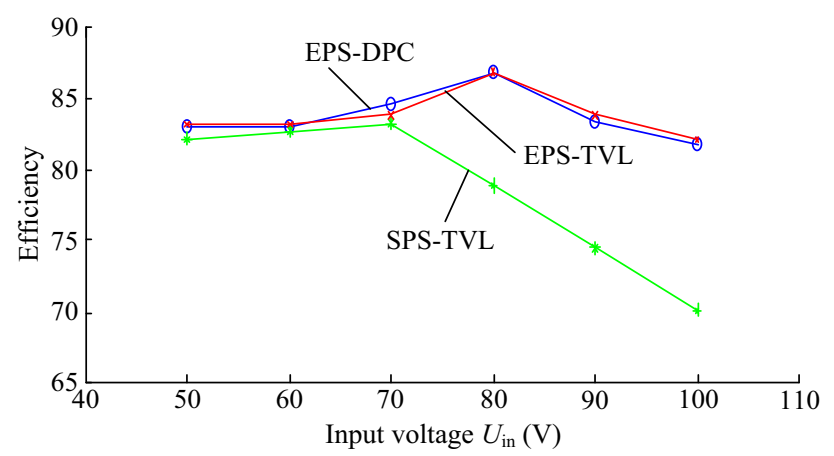

(b) Eficiency

Fig. 13 Experimental waveforms of current stress and efficiency with respect to input voltage $U_{\text {in }}$ in three control schemes

Start-up process performance of three schemes was compared. When the experimental parameters are set as $R=15 \Omega, U_{\mathrm{in}}=60 \mathrm{~V}$ and $U_{\mathrm{o}}^{*}=40 \mathrm{~V}$. Figure 14 shows experimental results of the input voltage, the inductor current and the output voltage in the DAB DC-DC converter system during start-up process for three schemes. It is clear in Fig. 14 that the start-up time is 370, 313, $100 \mathrm{~ms}$ in the SPS-TVL, EPS-TVL and EPS-DPC schemes, respectively. Thus, the EPS-DPC control has realized faster dynamic response than the others. Moreover, in the EPS-DPC, there is no overshoot in the output voltage during start-up process, and the current stress through transformer is much lower.

Dynamic responses to input voltage fluctuation in three schemes were studied. When the experimental parameters are set as $R=20 \Omega$ and $U_{\mathrm{o}}^{*}=40 \mathrm{~V}$, Figs. 15 and 16 show experimental results of the input voltage, the output voltage and inductor current in the DAB DC-DC converter with the input voltage step-change, where the input voltage $U_{\text {in }}$ steps down from $80 \mathrm{~V}$ to $70 \mathrm{~V}$ in Fig. 15, and conversely in Fig. 16. The SPS-TVL control in Figs. 15a and 16a and the EPS-TVL control in Figs. $15 \mathrm{~b}$ and $16 \mathrm{~b}$ take a relatively long settling time (over $100 \mathrm{~ms}$ ) in both the input voltage

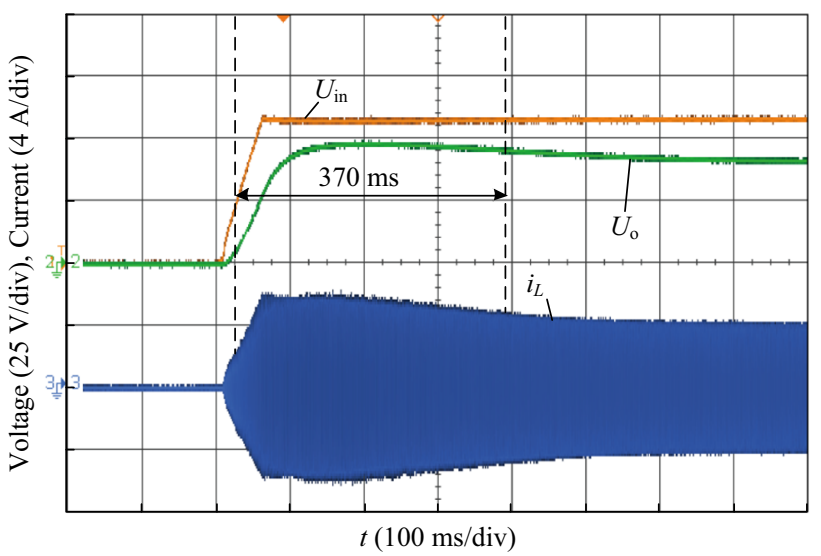

(a) SPS-TVL

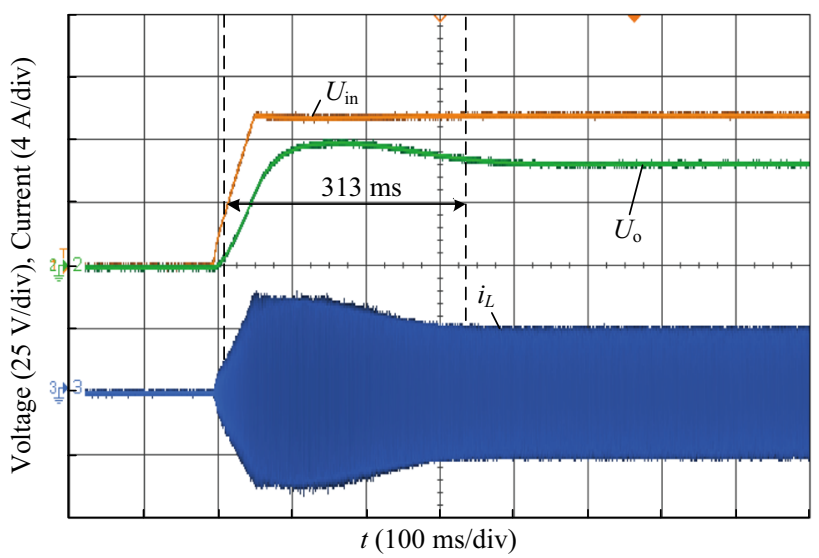

(b) EPS-TVL

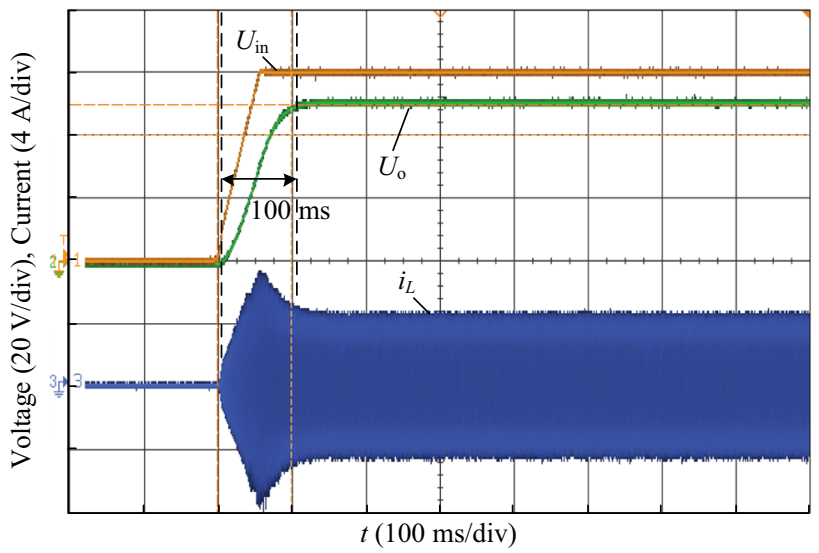

(c) EPS-DPC

Fig. 14 Experimental results during start-up process

step-down and step-up conditions for the output voltage to reach the desired value. In contrary, for the EPS-DPC scheme in Figs. 15c and 16c, the output voltage is almost unchanged during the input voltage step-change, which means its settling time is pretty short. In a word, the EPSDPC scheme can keep the output voltage constant, and achieve outstanding dynamic behavior when the input 


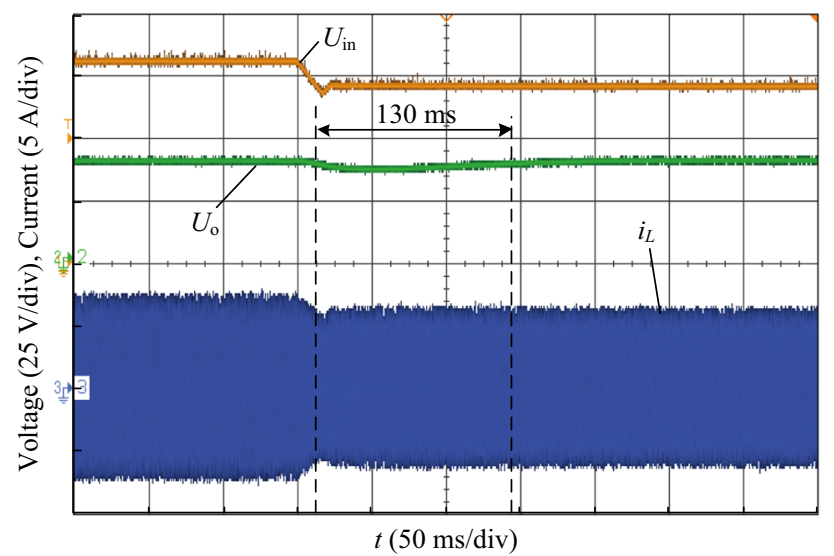

(a) SPS-TVL

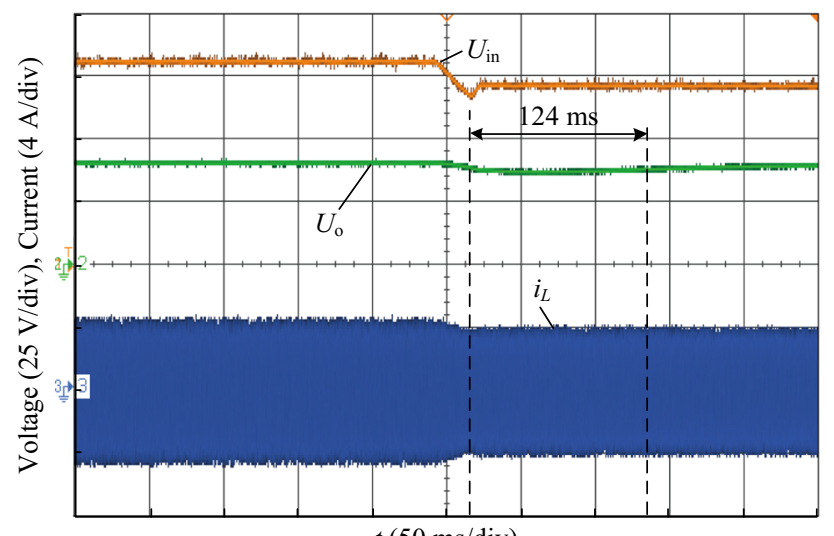

(b) EPS-TVL

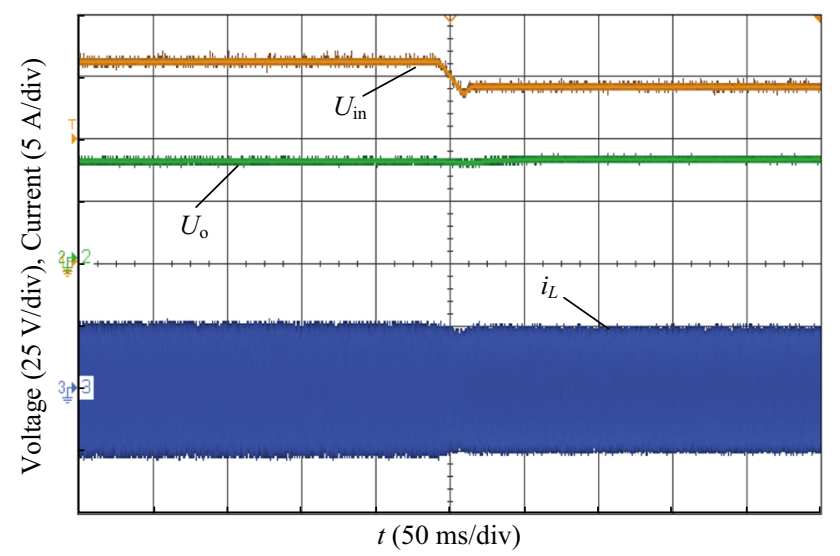

(c) EPS-DPC

Fig. 15 Experimental results when input voltage steps down from $80 \mathrm{~V}$ to $70 \mathrm{~V}$

voltage fluctuation occurs. Furthermore, the current stresses in EPS-DPC and EPS-TVL control schemes are smaller than that in SPS-TVL control scheme as well.

Comparison on dynamic responses to load disturbance of three schemes was carried out. When the experimental parameters are set as $U_{\text {in }}=65 \mathrm{~V}$ and $U_{\mathrm{o}}^{*}=40 \mathrm{~V}$, Figs. 17

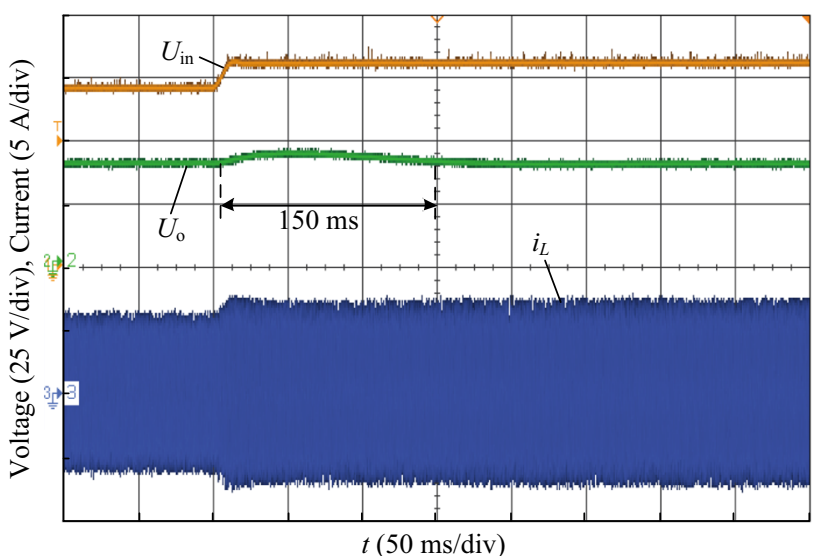

(a) SPS-TVL

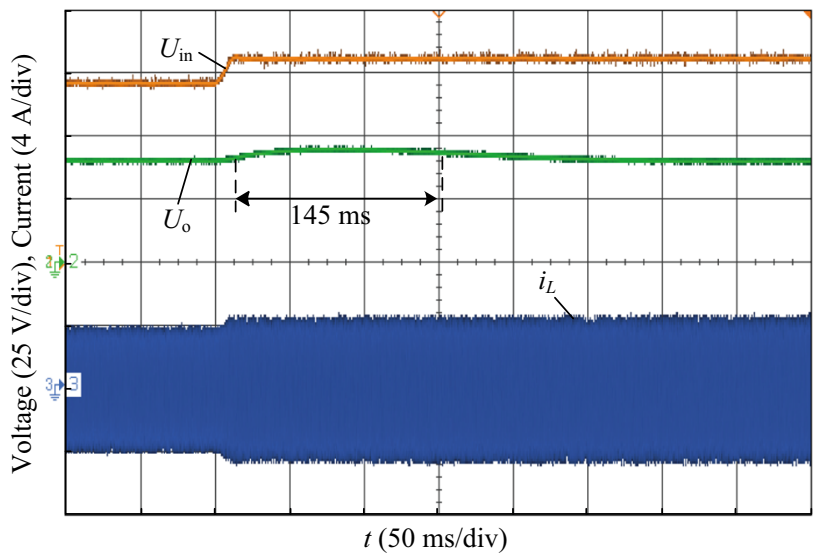

(b) EPS-TVL

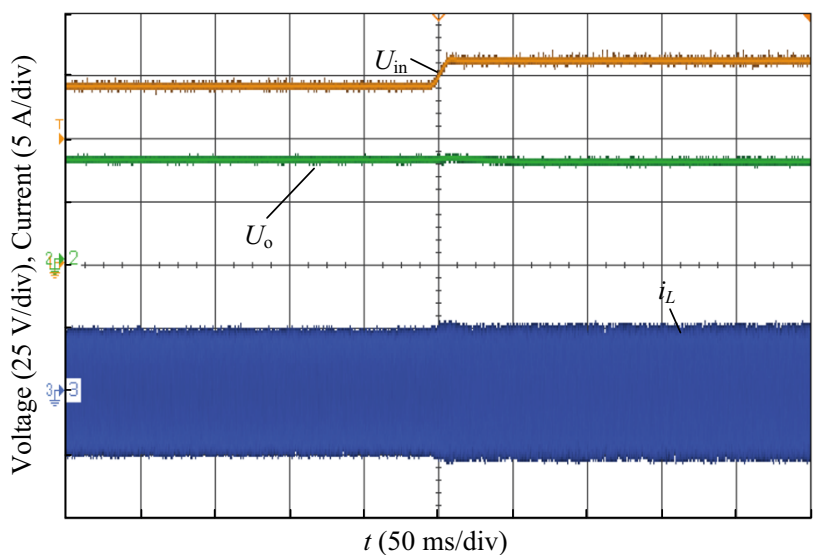

(c) EPS-DPC

Fig. 16 Experimental results when input voltage steps up from $70 \mathrm{~V}$ to $80 \mathrm{~V}$

and 18 show experimental results of the input voltage, the output voltage and inductor current in the adopted $\mathrm{DAB}$ DC-DC converter with a load step-change, where the load steps from 15 to $20 \Omega$ in Fig. 17, and conversely in Fig. 18. In SPS-TVL control in Figs. 17a and 18a and EPSTVL control in Figs. 17b and 18b, the transient responses 


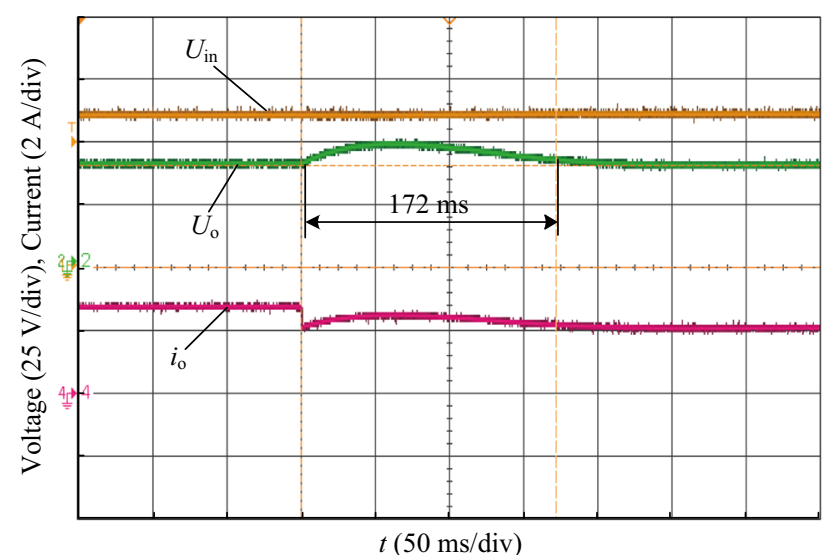

(a) SPS-TVL

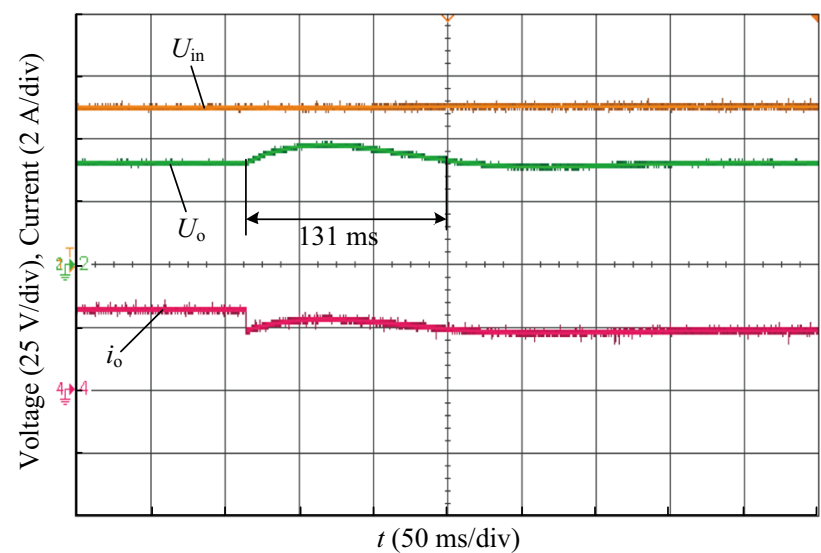

(b) EPS-TVL

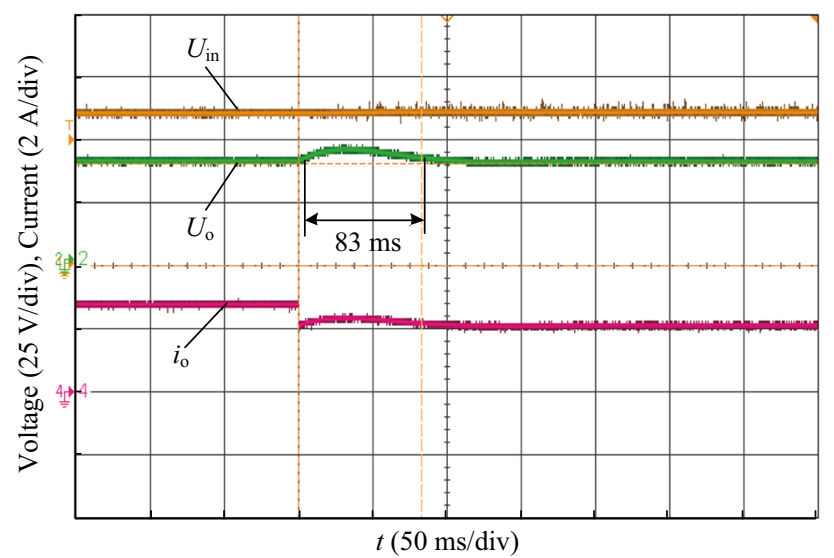

(c) EPS-DPC

Fig. 17 Experimental results when the load steps up from 15 to $20 \Omega$

of the output voltage are slow, with a relatively long settling time (over $100 \mathrm{~ms}$ ) in both the load step-down and step-up conditions. The EPS-TVL control is a bit better in dynamic performances than the SPS-TVL control though. However, the EPS-DPC scheme in Figs. 17c and 18c outstands the EPS-TVL and SPS-TVL by short settling time (below $100 \mathrm{~ms}$ ) when the load disturbance occurs.

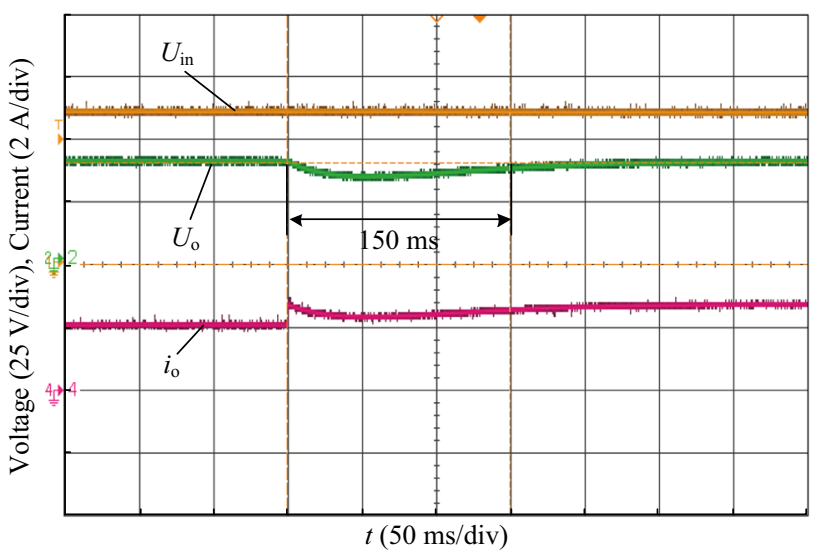

(a) SPS-TVL

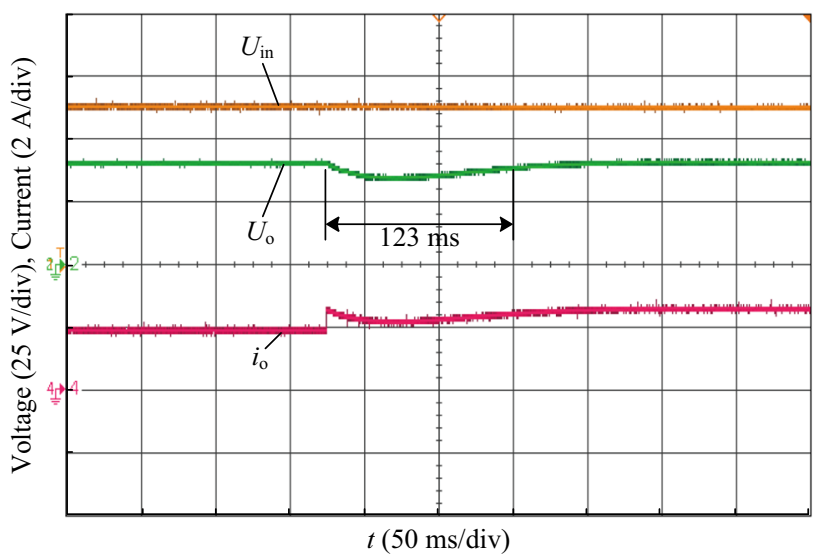

(b) EPS-TVL

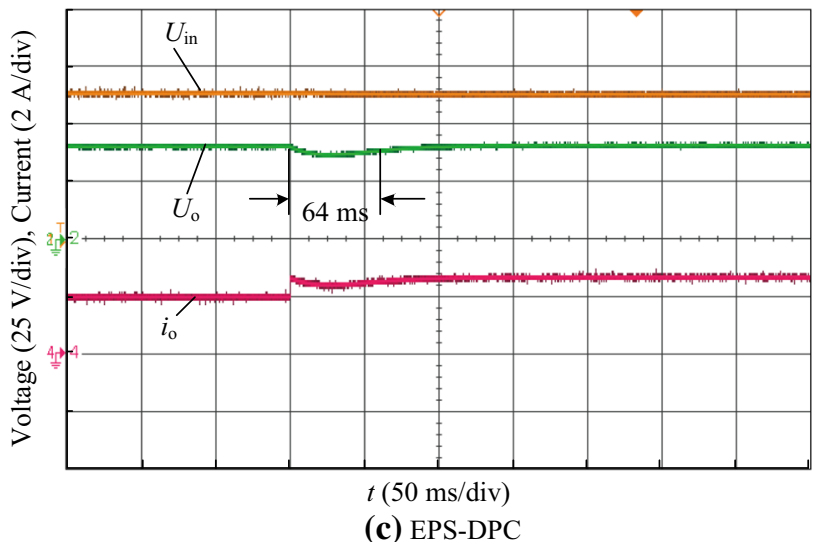

Fig. 18 Experimental results when load steps down from 20 to $15 \Omega$

\section{Conclusion}

In order to improve both efficiency and the output dynamic response of DAB DC-DC converters, a hybrid control scheme combining the extend-phase-shift control and direct power control is proposed in this paper. For DAB DC-DC converter applications, the proposed EPSDPC, the EPS-TVL and the SPS-TVL schemes are 
analyzed and compared in detail. A scale-down experimental prototype test is utilized to compare performances of these three control schemes and verify benefits of the proposed EPS-DPC. The conducted studies conclude that the proposed EPS-DPC scheme has following salient features:

1) EPS-DPC scheme can achieve the best dynamic performance under start-up process, input voltage fluctuation, and load disturbance circumstances when compared with SPS-TVL and EPS-TVL.

2) EPS-DPC, as well as EPS-TVL, can realize higher converter efficiency than SPS-TVL, especially in relatively high input voltage conditions.

Acknowledgement This work was supported by the National Natural Science Foundation of China (No. 51577160).

Open Access This article is distributed under the terms of the Creative Commons Attribution 4.0 International License (http:// creativecommons.org/licenses/by/4.0/), which permits unrestricted use, distribution, and reproduction in any medium, provided you give appropriate credit to the original author(s) and the source, provide a link to the Creative Commons license, and indicate if changes were made.

\section{References}

[1] Doncker RWAAD, Divan DM, Kheraluwala MH (1991) A three-phase soft-switched high-power-density DC/DC converter for high-power applications. IEEE Trans Ind Appl 27(1):63-73

[2] Aggeler D, Biela J, Inoue S et al (2007) Bi-directional isolated DC-DC converter for next-generation power distribution-comparison of converters using $\mathrm{Si}$ and $\mathrm{SiC}$ devices. In: Proceedings of power conversion conference, Nagoya, Japan, 2-5 April 2007, pp 510-517

[3] Inoue S, Akagi H (2006) A bi-directional isolated DC/DC converter as a core circuit of the next-generation mediumvoltage power conversion system. In: Proceeding of 37th power electronics specialists conference, Jeju, South Korea, 18-22 June 2006, 7 pp

[4] Zhao B, Yu Q, Sun W (2012) Extended-phase-shift control of isolated bidirectional DC-DC converter for power distribution in microgrid. IEEE Trans Power Electron 27(11):4667-4680

[5] Chiu HJ, Lin LW (2006) A bidirectional DC-DC converter for fuel cell electric vehicle driving system. IEEE Trans Power Electron 21(4):950-958

[6] Krismer F, Kolar JW (2012) Closed form solution for minimum conduction loss modulation of DAB converters. IEEE Trans Ind Electron 27(1):174-188

[7] Krismer F, Kolar JW (2010) Accurate power loss model derivation of a high-current dual active bridge converter for an automotive application. IEEE Trans Power Electron 57(3):881-891

[8] Krismer F, Kolar JW (2012) Efficiency-optimized high-current dual active bridge converter for automotive applications. IEEE Trans Ind Electron 59(7):2745-2760

[9] Inoue S, Akagi H (2007) A bidirectional DC-DC converter for an energy storage system with galvanic isolation. IEEE Trans Power Electron 22(6):2299-2306
[10] Tan NML, Abe T, Akagi H (2012) Design and performance of a bidirectional isolated DC-DC converter for a battery energy storage system. IEEE Trans Power Electron 27(3):1237-1248

[11] Los M, Drabek P, Cedl M (2010) The control algorithms of traction drive with medium-frequency transformer and two modules of single phase matrix converters. In: Proceedings of international power electronics and motion control conference, Ohrid, Macedonia, 6-8 Sept 2010, pp 143-146

[12] Blahnik V, Peroutka Z, Molnar J et al (2008) Control of primary voltage source active rectifiers for traction converter with medium-frequency transformer. In: Proceedings of power electronics and motion control conference, Poznan, Poland, 1-3 Sept 2008, pp 1535-1541

[13] Zhao C, Round SD, Kolar JW (2010) Full-order averaging modeling of zero-voltage-switching phase-shift bidirectional dcdc converters. IET Power Electron 3(3):400-410

[14] Qin H, Kimball JW (2012) Generalized average modeling of dual active bridge DC-DC converter. IEEE Trans Power Electron 27(4):2078-2084

[15] Krismer F, Kolar JW (2009) Accurate small-signal model for the digital control of an automotive bidirectional dual active bridge. IEEE Trans Power Electron 24(12):2756-2768

[16] Segaran D, Holmes DG, McGrath BP (2013) Enhanced load step response for a bidirectional DC-DC converter. IEEE Trans Power Electron 28(1):371-379

[17] Bai H, Mi C, Wang C et al (2008) The dynamic model and hybrid phase-shift control of a dual-active-bridge converter. In: Proceedings of IECON, Orlando, USA, 10-13 Nov 2008, 6 pp

[18] Bai H, Nie Z, Mi C (2010) Experimental comparison of traditional phase-shift, dual-phase-shift, and model-based control of isolated bidirectional DC-DC converters. IEEE Trans Power Electron 25(6): 1444-1449

[19] Zhao B, Yu Q, Sun W (2013) Efficiency characterization and optimization of isolated bidirectional DC-DC converter based on dual-phase-shift control for DC distribution application. IEEE Trans Ind Electron 28(4):1171-1727

[20] Oggier G, Oliva R (2009) Switching control strategy to minimize dual active bridge converter losses. IEEE Trans Power Electron 24(7):1826-1838

[21] Bai H, Mi C (2008) Eliminate reactive power and increase system efficiency of isolated bidirectional dual-active-bridge DC-DC converters using novel dual-phase-shift control. IEEE Trans Power Electron 23(6):2905-2914

[22] Vazquez S, Sanchez JA, Carrasco JM et al (2008) A modelbased direct power control for three-phase power converters. IEEE Trans Power Electron 55(4):1647-1657

[23] Zhang Y, Qu C (2015) Direct power control of a pulse width modulation rectifier using space vector modulation under unbalanced grid voltages. IEEE Trans Power Electron 30(10):5892-5910

[24] Hou N, Song W, Wu M (2016) Minimum-current-stress scheme of dual active bridge DC-DC converter with unified phase-shift control. IEEE Trans Power Electron 31(12):8552-8561

Nie HOU received the B.S. degree and M.S degree in electrical engineering from Southwest Jiaotong University, Chengdu, China, in 2014 and 2017, respectively. He is currently working toward his Ph.D degree in electrical engineering in University of Alberta, Edmonton, Canada. His current research interests include digital control and optimization methods of DC-DC converter, and DC distribution system.

Wensheng SONG received the B.S. degree in electronic and information engineering, the Ph.D degree in electrical engineering 
from Southwest Jiaotong University, Chengdu, China, in 2006 and 2011, respectively, where he is currently an associate professor in the School of Electrical Engineering. From Sep. 2009 to Sep. 2010, he was a visiting scholar with the department of electrical engineering and computer science, University of California, Irvine, USA. From Jul. 2015 to Dec. 2015, he was a visiting scholar at University of Alberta, Edmonton, Canada. His current research interests include digital control and modulation methods of electrical AC-DC-AC railway traction drive systems, and multilevel converters.

Yutong ZHU received the M.S. degree in electrical engineering from University of Wisconsin-Madison in Madison, WI, USA, in 2016 and the B.S. degree in electrical engineering from Zhejiang University in Hangzhou, China, in 2013. Currently she is working in China Academy of Railway Science (CARS) in Beijing, China. Her research interests include AC-DC-AC railway traction drive systems and WBG power devices.
Xiao SUN was born in Dezhou, Shangdong, China, in 1991, received the B.S. degree and M.S degree in electrical engineering from Southwest Jiaotong University, Chengdu, China, in 2014 and 2017, respectively. From Sep. 2017, She is currently working in State Grid Corporation of China, Tsingtao, China. Her current research interests include power converter technology, and power distribution system.

Wei LI received the B.S. degree in electronic engineering from North Jiaotong University, the M.S degree in power system from China Academy of Railway Sciences and Ph.D degree in control theory and control engineering from Chinese Academy of Scinces, Beijing, China, in 1996, 2002 and 2006, respectively. He is currently an associate researcher in China Academy of Railway Sciences and his current research interests include traction driver system and power converter technology. 